OPEN ACCESS

Edited by:

Sebastian von Peter,

Charité Universitätsmedizin Berlin,

Germany

Reviewed by:

Martin Heinze,

Immanuel Klinik Rüdersdorf, Germany

Stefan Weinmann,

Vivantes Klinikum, Germany

${ }^{*}$ Correspondence:

Michael P. Hengartner

michaelpascal.hengartner@zhaw.ch

Specialty section: This article was submitted to

Public Mental Health,

a section of the journal

Frontiers in Psychiatry

Received: 23 October 2017 Accepted: 24 November 2017 Published: 07 December 2017

Citation:

Hengartner MP (2017) Methodological Flaws, Conflicts of Interest, and Scientific Fallacies: Implications for the Evaluation of Antidepressants' Efficacy and Harm.

Front. Psychiatry 8:275.

doi: 10.3389/fpsyt.2017.00275
Methodological Flaws, Conflicts of Interest, and Scientific Fallacies: Implications for the Evaluation of Antidepressants' Efficacy and Harm

\author{
Michael P. Hengartner* \\ Department of Applied Psychology, Zurich University of Applied Sciences (ZHAW), Zurich, Switzerland
}

Background: In current psychiatric practice, antidepressants are widely and with ever-increasing frequency prescribed to patients. However, several scientific biases obfuscate estimates of antidepressants' efficacy and harm, and these are barely recognized in treatment guidelines. The aim of this mini-review is to critically evaluate the efficacy and harm of antidepressants for acute and maintenance treatment with respect to systematic biases related to industry funding and trial methodology.

Methods: Narrative review based on a comprehensive search of the literature.

Results: It is shown that the pooled efficacy of antidepressants is weak and below the threshold of a minimally clinically important change once publication and reporting biases are considered. Moreover, the small mean difference in symptom reductions relative to placebo is possibly attributable to observer effects in unblinded assessors and patient expectancies. With respect to trial dropout rates, a hard outcome not subjected to observer bias, no difference was observed between antidepressants and placebo. The discontinuation trials on the efficacy of antidepressants in maintenance therapy are systematically flawed, because in these studies, spontaneous remitters are excluded, whereas half of all patients who remitted on antidepressants are abruptly switched to placebo. This can cause a severe withdrawal syndrome that is easily misdiagnosed as a relapse when assessed on subjective symptom rating scales. In accordance, the findings of naturalistic long-term studies suggest that maintenance therapy has no clear benefit, and non-drug users do not show increased recurrence rates. Moreover, a growing body of evidence from hundreds of randomized controlled trials suggests that antidepressants cause suicidality, but this risk is underestimated because data from industry-funded trials are systematically flawed. Unselected, population-wide observational studies indicate that depressive patients who use antidepressants are at an increased risk of suicide and that they have a higher rate of all-cause mortality than matched controls.

Conclusion: The strong reliance on industry-funded research results in an uncritical approval of antidepressants. Due to several flaws such as publication and reporting bias, unblinding of outcome assessors, concealment and recoding of serious adverse events, the efficacy of antidepressants is systematically overestimated, and harm is systematically underestimated. Therefore, I conclude that antidepressants are largely ineffective and potentially harmful.

Keywords: antidepressants, selective serotonin reuptake inhibitor, efficacy, harms, suicide, serious adverse events, bias 
Treatment guidelines for major depression (MD) in Europe and the United States typically recommend antidepressant medication with or without psychotherapy (1). In particular, the American Psychiatric Association (APA) advises antidepressants as firstline treatment for all forms of $\mathrm{MD}$, including mild episodes (2). The APA further recommends antidepressants not only for acute treatment but also for continuation therapy (approximately 4-9 months) and maintenance therapy (several years up to indefinite time). Overall, the APA treatment guidelines for adult MD provide are very favorable risk-benefit analysis for selective serotonin reuptake inhibitors (SSRIs) and serotonin norepinephrine reuptake inhibitors (SNRIs), suggesting that these drug classes are highly effective, well tolerated, and safe. However, paradoxically the massive increase in antidepressant prescription rates over the last three decades did not translate into measurable public health benefits (3-5). From a public mental health perspective, we would expect that effective antidepressants reduce the prevalence and burden of MD, unless the scientific evidence is unreliable. In the following, I will therefore provide a critical reexamination of antidepressants' efficacy and safety. I will mostly rely on evidence from randomized controlled trials (RCTs), as these are considered gold-standard to establish causality and efficacy of clinical interventions. Although RCTs are less prone to bias than observational studies, they also have limitations, in particular in industry-funded pharmacological research (6-8). A special emphasis will hence be given to the unduly ties between scientific psychiatry and the pharmaceutical industry (9-11). I will first examine antidepressants' efficacy for acute treatment, proceed with a review of their efficacy for continuation and maintenance therapy, and close with an outline of severe harms. Scientific biases will be discussed in context, as they substantially inflate antidepressants' public health significance.

\section{ACUTE THERAPY}

Research funded by the pharmaceutical industry is systematically biased toward their marketed products (12-15). That is, the estimated efficacy of pharmaceutical products is significantly higher when the research was funded by the industry compared to non-industry funding, but this difference is not attributable to differences in the study quality $(13,14)$. For instance, research funded and conducted by the NIMH largely failed to demonstrate a clear difference between antidepressants and placebo, despite adequate sample sizes and strong RCT methodology [e.g., Ref. $(16,17)]$. Research conducted by authors with financial conflicts of interest (COI) related to the pharmaceutical industry is likewise systematically biased in favor of the industry's vested interests (18-20). That is, efficacy of pharmacological treatments is overestimated, whereas harms are underreported. Due to the pervasive entanglement of psychiatry with the pharmaceutical industry $(9-11,21)$, these biases undermine the validity of the scientific literature on antidepressants' efficacy. For instance, it is now clearly established that many industry-funded antidepressant trials were never published, and if published, some results were inadequately presented in a favorable way $(15,22,23)$. That is, trials with negative results are either not published or negative results are distorted to appear positive $(7,24)$. Outcome reporting bias is a common scientific flaw and means that authors conceal the effect of the prespecified primary efficacy outcome and instead choose to report the most convenient from different secondary outcomes (25). Also, harms and serious adverse events of antidepressants are often not reported, and such concealment is strongly related to authors' financial COI and industry funding (26). Another common flaw is to report efficacy based on drugplacebo differences in response and remission rates (27). To come at binary constructs such as response and remission, continuous symptom rating scales are dichotomized along arbitrary cut-offs. However, methodologists have vigorously advised against the use of dichotomization (28-30) because it produces, among others, systematically inflated effect sizes (31-33). Most short-term efficacy RCTs were conducted to receive marketing approval from regulatory agencies. To ensure that drug-placebo differences in the outcome are clearly attributable to the intervention, efficacy RCT use preselected groups of participants tested under ideal clinical settings (34). Therefore, trial conditions markedly deviate from real-world clinical settings, and the included participants are not representative of the patient population seen in routine clinical practice. Specifically, RCT exclude a majority of MD patients due to comorbid disorders and suicidal ideation (35). Included participants are less impaired and have a higher level of functioning $(36,37)$, and it has been demonstrated that they respond better to antidepressants than the average real-world patient (36).

Meta-analyses that include unpublished trials and that examine mean differences in continuous depression rating scales report statistically significant but marginally small differences between antidepressants and placebo $(23,38-40)$. More recent studies have suggested that drug-placebo differences are larger when instead of heterogeneous sum-scores, which also include somatic symptoms, only depressive core symptoms were considered (41, 42). However, the results barely support this conclusion, because estimated effect sizes are still small and considered clinically insignificant per convention. But what exactly means clinically significant? In general, clinical significance refers to an effect size $d$ or $g>0.5$ or a difference $>3$ points on the Hamilton Depression Scale for Depression (HAMD) (38). However, empirical evidence has suggested that at least 7 points on the HAMD or an effect size $>0.87$ is necessary for a clinician to observe a minimal improvement in depression symptoms (43). Based on these criteria, the efficacy of antidepressants is impossible to discern from placebo effects in any meta-analysis conducted thus far.

Some authors deem the small difference between antidepressants and placebo a methodological artifact $(27,44-46)$. For instance, Chen et al. (47) re-analyzed a double-blind RCT with the treatment arms antidepressant (sertraline), St John's Wort, and placebo, with respect to patients' treatment beliefs. Depression symptom reduction did not differ between treatment arms. However, independent of actual treatment received, patients who believed they receive placebo showed less improvement, and patients who correctly guessed that they receive placebo improved even less. One hypothesis states that the assumption of blinding is violated even in double-blind RCT, because both patients and outcome assessors may correctly guess who receives placebo due to a suspicious lack of side effects (44). Such unblinding effects inflate the apparent efficacy of antidepressants, because 
unblinded outcome assessors systematically overestimate the efficacy of experimental interventions $(48,49)$. Taking into account the unblinding bias, Gotzsche (50) calculated that the average efficacy of antidepressants does not differ from placebo. More reliable than differences in subjective rating scales are objective outcomes such as premature treatment termination. Several meta-analyses did not detect a noticeable difference between antidepressant and placebo arms with respect to overall dropout rates in short-term RCT (51-53). Assuming that patients prematurely terminate a free treatment only if they perceived it as useless or even harmful (54), these findings indicate that the average patient experiences no clear benefits from antidepressants.

\section{CONTINUATION AND MAINTENANCE THERAPY}

There are two trial designs to examine effects of long-term antidepressant use. The first is the long-term parallel-arm efficacy trial, where responders to both antidepressants and placebo are followed up. The second, much more common design, is the discontinuation trial, where antidepressant responders are randomly assigned to either continued therapy or rapid discontinuation and switching to placebo. In a recent meta-analysis of long-term parallel-arm RCT of 6-8 months duration, no difference between groups was found with respect to both remission and treatment discontinuation rates (55). Meta-analyses of discontinuation trials suggest that long-term antidepressant use may prevent relapse, but only very few trials have empirically examined that effect for 2 years or more $(56,57)$. In addition, effects in discontinuation trials are difficult to interpret, because they exclusively include participants who remitted during acute open-label antidepressant treatment. Therefore, it is not known how many patients would have relapsed if they had remitted spontaneously, i.e., without prior acute antidepressant therapy (55). This is a serious issue, because it has been argued that antidepressants prospectively increase the relapse rate due to pharmacodynamics $(58,59)$. Another problem with discontinuation trials is the rapid discontinuation of antidepressants and immediate switching to placebo given the ambiguous nature of subsequently emerging symptoms (60). Research has shown that antidepressants may cause severe withdrawal symptoms after discontinuation $(61,62)$, which in some cases persist for months and therefore are easily misdiagnosed as depression relapse (63). That is, a substantial portion of depression relapses in discontinuation trials are in fact discontinuation or withdrawal syndromes. In support of this notion, it has been shown that rapid discontinuation of antidepressants, relative to gradual tapering, prospectively increases the risk of depression reoccurrence (64), but note that even very slow tapering may cause severe mood disturbances $(61,63)$. It has further been shown that the preventive effects of antidepressants dissipate after 1-3 months (65). At the latest after 6 months, the risk of re-occurrences is identical in antidepressant and placebo arms (66).

Some authors suggest that long-term antidepressant use may increase the vulnerability for (recurrent) depression due to neurochemical sensitization $(58,59)$. In support of this thesis, a recent meta-analysis revealed that the relapse risk after antidepressant discontinuation correlates positively with the duration of preceding acute therapy (57). That is, the longer antidepressant treatment, the higher the relapse risk after discontinuation. Moreover, several meta-analyses showed that psychotherapy reduces the long-term relapse risk significantly more than pharmacotherapy, despite both therapies being equally effective during acute therapy $(67,68)$. A systematic review of observational long-term studies found that maintenance therapy conveys no clear benefits: antidepressant users had no better long-term outcome than non-users (69). In an observational study of patients with remitted recurrent depression, maintenance therapy related to a higher recurrence rate than discontinuation (70). Other observational studies likewise suggest that antidepressant use may worsen the long-term outcome $(71,72)$, but causality is uncertain due to confounding by indication. A few highly cited epidemiologic studies reported that long-term antidepressant medication relates to lower relapse rates, but these have been shown to be methodologically flawed: when properly analyzed, maintenance therapy is not associated with lower relapse rates (73). Finally, according to the re-analysis of STAR ${ }^{\star} \mathrm{D}(54)$, only $5.8 \%$ of all patients who entered continuation therapy were still in remission after 12 -month follow-up. A total of $37.4 \%$ of remitted patients, and altogether $64.4 \%$ of improved patients had a relapse within the first 12 months of continuation therapy.

\section{SEVERE HARM}

In children, adolescents and young adults up to 25 years, several meta-analyses of short-term RCT have confirmed that antidepressants, relative to placebo, significantly increase suicide risk (74-77). Moreover, there is now increasing evidence from several RCT and a few well-controlled observational studies that antidepressants may increase suicide risk in adults of any age. On the basis of Bayes' statistics, Aursnes et al. (78) calculated that paroxetine, compared to placebo, may cause suicide with a certainty of $98-99 \%$. Baldessarini et al. (79) meta-analyzed long-term RCT for adult MD and found a markedly increased rate of completed and attempted suicides in antidepressant arms compared to placebo. With respect to suicidality, i.e., suicide attempts, self-harm, and suicidal ideation combined, a metaanalysis found that antidepressants convey a 2.5 times increased risk (80). Another meta-analysis found that paroxetine increases suicidality in adults aged 18 years and older by a factor 2.6 (51). Gunnell et al. (81) found weak meta-analytic evidence for a slightly increased risk of self-harm in antidepressant users, but not with respect to suicides or suicidal ideation. The recent metaanalysis by Sharma et al. (75) did not find increased suicidality in adult antidepressant users relative to placebo. In contrast to that, Stone et al. (76) meta-analyzed data from pharmaceutical companies submitted to the FDA and found that suicidality was slightly increased in placebo groups for adults aged 25-64 years (relative risk: 1.3), and it was even markedly increased in adults aged 65 years and older (relative risk: 2.7). These findings suggest that antidepressants may protect against suicide in middle-aged and older adults, which conflicts with the findings of all other meta-analyses detailed above. However, the work by Stone et al. (76) was criticized, because many cases of suicidality were evidently missing in antidepressant treatment arms (50). In 
accordance, many authors concluded that industry-funded trials are unreliable, as they willingly underreport cases of suicidality in antidepressant arms $(80,81)$, for instance by coding suicide attempts as "emotional lability" (75).

Just as the apparent efficacy of antidepressants is overestimated due to publication and reporting biases $(15,23)$, the pharmaceutical industry conceals harms by underreporting serious adverse events $(14,52,82)$. Because RCT typically excludes severely impaired persons with suicidal ideation $(35,36)$, they run the risk to overlook a pernicious risk. Therefore, industry-funded research systematically underestimates the harm caused by their marketed drugs (14). Although scientifically less stringent (due to confounding by indication), I therefore need to consider well-controlled observational studies conducted by researchers without COI. An advantage of observational studies is that they can encompass much longer time frames than the short-term RCT typically lasting only 6-8 weeks. Due to much larger samples, observation studies allow for detecting harms occurring at low absolute frequency (34). A large naturalistic study with close to 240,000 persons with MD aged between 20 and 64 years found that antidepressant users committed 2.6 times more often suicide than non-users (83). Another well-controlled observational study based on a national register of 5,866 suicides showed that antidepressant use increases the odds of committing suicide 2.7 times in women and 4.3 times in men, with a clear increase in risk with higher age (84). Finally, several ecologic studies supposedly show a negative correlation between national antidepressant sales/ prescriptions and suicide rates (suggesting that antidepressants prevent suicide), but these studies are substantially flawed (85) and some were clearly disconfirmed $(3,5)$.

Naturalistic studies with high power have further shown that antidepressant use prospectively relates to all-cause mortality. For instance, in a study with over 60,000 patients with MD aged 65 years and older, it was shown that over a mean follow-up of 5.0 years, prescription of tricyclics increase the relative mortality rate by $16 \%$, SSRI by $54 \%$, and other antidepressants (mostly SNRI) by $66 \%$ (86). In another prospective observational study including over 136,000 postmenopausal women, it was shown that SSRI increase the relative mortality rate by $32 \%$ and tricyclics by $67 \%$ (87). Finally, a recent meta-analysis showed that antidepressants increase the all-cause mortality risk by $33 \%$ in the general population with no difference between SSRI and tricyclics (88). Due to thorough multivariate statistical modeling, it is unlikely that confounding by indication may account for all these effects. Moreover, in psychiatric outpatients, antidepressant use is higher in persons with low distress (89), whereas in primary care, most antidepressants are prescribed to persons without a psychiatric diagnosis (90). Hence, it is possible that confounding by indication may even underestimate the true harm attributable

\section{REFERENCES}

1. Davidson JR. Major depressive disorder treatment guidelines in America and Europe. J Clin Psychiatry (2010) 71:e04. doi:10.4088/JCP.9058se1c.04gry

2. American Psychiatric Association. Practice Guideline for the Treatment of Patients with Major Depressive Disorder. Washington, DC: American Psychiatric Association (2010). to antidepressant use. Therefore, a reasonable conclusion is that antidepressants disrupt adaptive bodily processes such as digestion, immune function, tissue repair, metabolism, etc., which may lead to premature death $(91,92)$.

\section{CONCLUSION}

The results of this mini-review suggest that the efficacy of antidepressants is systematically overestimated, while potential harms are underreported and neglected. Despite these alarming findings, thought leaders within mainstream psychiatry and official treatment guidelines strongly recommend antidepressant use for acute and long-term therapy. However, mainstream psychiatry is closely tied to the pharmaceutical industry, and most leading psychiatric experts receive substantial amounts of financial support from the industry $(9,11,21)$. Thus, it is crucial to reiterate that industryfunded trials and research conducted by authors with financial $\mathrm{COI}$ is systematically biased toward the pharmaceutical industry's vested interests $(13,14,20)$. The strong alliance between scientific psychiatry and the pharmaceutical industry is problematic and should be subjected to close scrutiny $(9-11,24)$. Moreover, there is an ongoing debate, whether antidepressant therapy is more efficacious in severe, rather endogenous MD compared to milder, reactive $\mathrm{MD}$ (27). Some meta-analytic evidence suggests that this is indeed the case (93), but other failed to replicate this finding (40). Finally, the evidence reviewed in this article relied mostly on RCT, which are also subject to bias $(34,94)$. Theoretically, these biases could result in an underestimation of antidepressant efficacy, but evidence from real-world effectiveness trials strongly argues otherwise, since real-world patients are more impaired and respond significantly worse to antidepressant therapy $(36,37)$. Finally, it has been argued that the efficacy of antidepressants is underestimated in more recent trials due to marked increases in placebo responses over time. However, that claim is false. A recent meta-analysis has clearly shown that the placebo response rate has been stable for almost 30 years now (95). As concerns treatment recommendations, my reading of the literature is that some patients may benefit from acute pharmacotherapy, but on average clinical benefits are debatable and should be weighed against adverse side effects $(38,39,51)$. Continuation and maintenance therapy is not recommended due to an apparent lack of clear clinical benefits $(54,55,96)$, coupled with a possibly increased vulnerability to chronic depression $(58,97)$, increased suicide risk $(79,83)$, and, in particular in older adults, higher all-cause mortality $(86,88,98)$.

\section{AUTHOR CONTRIBUTIONS}

$\mathrm{MH}$ conducted the literature review and wrote the entire manuscript.

3. Helgason T, Tomasson H, Zoega T. Antidepressants and public health in Iceland. Time series analysis of national data. Br JPsychiatry (2004) 184:157-62. doi:10.1192/bjp.184.2.157

4. Jorm AF, Patten SB, Brugha TS, Mojtabai R. Has increased provision of treatment reduced the prevalence of common mental disorders? Review of the evidence from four countries. World Psychiatry (2017) 16:90-9. doi:10.1002/ wps. 20388 
5. Zahl PH, De Leo D, Ekeberg O, Hjelmeland H, Dieserud G. The relationship between sales of SSRI, TCA and suicide rates in the Nordic countries. BMC Psychiatry (2010) 10:62. doi:10.1186/1471-244X-10-62

6. Naci H, Ioannidis JP. How good is "evidence" from clinical studies of drug effects and why might such evidence fail in the prediction of the clinical utility of drugs? Annu Rev Pharmacol Toxicol (2015) 55:169-89. doi:10.1146/ annurev-pharmtox-010814-124614

7. Lexchin J. Those who have the gold make the evidence: how the pharmaceutical industry biases the outcomes of clinical trials of medications. Sci Eng Ethics (2012) 18:247-61. doi:10.1007/s11948-011-9265-3

8. Moncrieff J. Are antidepressants overrated? A review of methodological problems in antidepressant trials. J Nerv Ment Dis (2001) 189:288-95. doi:10.1097/00005053-200105000-00003

9. Fava GA. Financial conflicts of interest in psychiatry. World Psychiatry (2007) 6:19-24.

10. Moncrieff J. Co-opting psychiatry: the alliance between academic psychiatry and the pharmaceutical industry. Epidemiol Psichiatr Soc (2007) 16:192-6.

11. Cosgrove L, Bursztajn HJ, Krimsky S, Anaya M, Walker J. Conflicts of interest and disclosure in the American Psychiatric Association's Clinical Practice Guidelines. Psychother Psychosom (2009) 78:228-32. doi:10.1159/ 000214444

12. Flacco ME, Manzoli L, Boccia S, Capasso L, Aleksovska K, Rosso A, et al. Head-to-head randomized trials are mostly industry sponsored and almost always favor the industry sponsor. J Clin Epidemiol (2015) 68:811-20. doi:10.1016/j.jclinepi.2014.12.016

13. Lexchin J, Bero LA, Djulbegovic B, Clark O. Pharmaceutical industry sponsorship and research outcome and quality: systematic review. BMJ (2003) 326:1167-70. doi:10.1136/bmj.326.7400.1167

14. Lundh A, Sismondo S, Lexchin J, Busuioc OA, Bero L. Industry sponsorship and research outcome. Cochrane Database Syst Rev (2012) 12:MR000033. doi:10.1002/14651858.MR000033.pub2

15. Melander H, Ahlqvist-Rastad J, Meijer G, Beermann B. Evidence b(i)ased medicine - selective reporting from studies sponsored by pharmaceutical industry: review of studies in new drug applications. BMJ (2003) 326:1171-3. doi:10.1136/bmj.326.7400.1171

16. Hypericum Depression Trial Study Group. Effect of Hypericum perforatum (St John's wort) in major depressive disorder: a randomized controlled trial. JAMA (2002) 287:1807-14. doi:10.1001/jama.287.14.1807

17. Shea MT, Elkin I, Imber SD, Sotsky SM, Watkins JT, Collins JF, et al. Course of depressive symptoms over follow-up. Findings from the National Institute of Mental Health Treatment of Depression Collaborative Research Program. Arch Gen Psychiatry (1992) 49:782-7. doi:10.1001/archpsyc. 1992. 01820100026006

18. Bekelman JE, Li Y, Gross CP. Scope and impact of financial conflicts of interest in biomedical research: a systematic review. JAMA (2003) 289:454-65. doi:10.1001/jama.289.4.454

19. Friedman LS, Richter ED. Relationship between conflicts of interest and research results. JGen Intern Med (2004) 19:51-6. doi:10.1111/j.1525-1497.2004. 30617.x

20. Perlis RH, Perlis CS, Wu Y, Hwang C, Joseph M, Nierenberg AA. Industry sponsorship and financial conflict of interest in the reporting of clinical trials in psychiatry. Am J Psychiatry (2005) 162:1957-60. doi:10.1176/appi. ajp.162.10.1957

21. Cosgrove L, Krimsky S. A comparison of DSM-IV and DSM-5 panel members' financial associations with industry: a pernicious problem persists. PLoS Med (2012) 9:e1001190. doi:10.1371/journal.pmed.1001190

22. Eyding D, Lelgemann M, Grouven U, Harter M, Kromp M, Kaiser T, et al. Reboxetine for acute treatment of major depression: systematic review and meta-analysis of published and unpublished placebo and selective serotonin reuptake inhibitor controlled trials. BMJ (2010) 341:c4737. doi:10.1136/bmj. c4737

23. Turner EH, Matthews AM, Linardatos E, Tell RA, Rosenthal R. Selective publication of antidepressant trials and its influence on apparent efficacy. N Engl J Med (2008) 358:252-60. doi:10.1056/NEJMsa065779

24. Every-Palmer S, Howick J. How evidence-based medicine is failing due to biased trials and selective publication. JEval Clin Pract (2014) 20:908-14. doi:10.1111/jep.12147

25. Dwan K, Altman DG, Arnaiz JA, Bloom J, Chan AW, Cronin E, et al. Systematic review of the empirical evidence of study publication bias and outcome reporting bias. PLoS One (2008) 3:e3081. doi:10.1371/journal.pone. 0003081

26. Ebrahim S, Bance S, Athale A, Malachowski C, Ioannidis JPA. Metaanalyses with industry involvement are massively published and report no caveats for antidepressants. J Clin Epidemiol (2016) 70:155-63. doi:10.1016/ j.jclinepi.2015.08.021

27. Moncrieff J, Kirsch I. Efficacy of antidepressants in adults. BMJ (2005) 331:155-7. doi:10.1136/bmj.331.7509.155

28. Altman DG, Royston P. The cost of dichotomising continuous variables. BMJ (2006) 332:1080. doi:10.1136/bmj.332.7549.1080

29. MacCallum RC, Zhang S, Preacher KJ, Rucker DD. On the practice of dichotomization of quantitative variables. Psychol Methods (2002) 7:19-40. doi:10.1037/1082-989X.7.1.19

30. Naggara O, Raymond J, Guilbert F, Roy D, Weill A, Altman DG. Analysis by categorizing or dichotomizing continuous variables is inadvisable: an example from the natural history of unruptured aneurysms. AJNR Am J Neuroradiol (2011) 32:437-40. doi:10.3174/ajnr.A2425

31. Kirsch I, Moncrieff J. Clinical trials and the response rate illusion. Contemp Clin Trials (2007) 28:348-51. doi:10.1016/j.cct.2006.10.012

32. Ragland DR. Dichotomizing continuous outcome variables: dependence of the magnitude of association and statistical power on the cutpoint. Epidemi$\log y$ (1992) 3:434-40. doi:10.1097/00001648-199209000-00009

33. Rossler W, Ajdacic-Gross V, Riecher-Rossler A, Angst J, Hengartner MP. Does menopausal transition really influence mental health? Findings from the prospective long-term Zurich study. World Psychiatry (2016) 15:146-54. doi:10.1002/wps.20319

34. Silverman SL. From randomized controlled trials to observational studies. Am J Med (2009) 122:114-20. doi:10.1016/j.amjmed.2008.09.030

35. Zimmerman M, Mattia JI, Posternak MA. Are subjects in pharmacological treatment trials of depression representative of patients in routine clinical practice? Am J Psychiatry (2002) 159:469-73. doi:10.1176/appi.ajp.159.3.469

36. Wisniewski SR, Rush AJ, Nierenberg AA, Gaynes BN, Warden D, Luther JF, et al. Can phase III trial results of antidepressant medications be generalized to clinical practice? A STAR*D report. Am J Psychiatry (2009) 166:599-607. doi:10.1176/appi.ajp.2008.08071027

37. Zimmerman M, Chelminski I, Posternak MA. Generalizability of antidepressant efficacy trials: differences between depressed psychiatric outpatients who would or would not qualify for an efficacy trial. Am J Psychiatry (2005) 162:1370-2. doi:10.1176/appi.ajp.162.7.1370

38. Jakobsen JC, Katakam KK, Schou A, Hellmuth SG, Stallknecht SE, LethMoller K, et al. Selective serotonin reuptake inhibitors versus placebo in patients with major depressive disorder. A systematic review with metaanalysis and Trial Sequential Analysis. BMC Psychiatry (2017) 17:58. doi:10.1186/s12888-016-1173-2

39. Kirsch I, Deacon BJ, Huedo-Medina TB, Scoboria A, Moore TJ, Johnson BT. Initial severity and antidepressant benefits: a meta-analysis of data submitted to the Food and Drug Administration. PLoS Med (2008) 5:e45. doi:10.1371/ journal.pmed.0050045

40. Gibbons RD, Hur K, Brown CH, Davis JM, Mann JJ. Benefits from antidepressants: synthesis of 6-week patient-level outcomes from double-blind placebo-controlled randomized trials of fluoxetine and venlafaxine. Arch Gen Psychiatry (2012) 69:572-9. doi:10.1001/archgenpsychiatry.2011.2044

41. Chekroud AM, Gueorguieva R, Krumholz HM, Trivedi MH, Krystal JH, McCarthy G. Reevaluating the efficacy and predictability of antidepressant treatments: a symptom clustering approach. JAMA Psychiatry (2017) 74:370-8. doi:10.1001/jamapsychiatry.2017.0025

42. Hieronymus F, Emilsson JF, Nilsson S, Eriksson E. Consistent superiority of selective serotonin reuptake inhibitors over placebo in reducing depressed mood in patients with major depression. Mol Psychiatry (2016) 21:523-30. doi:10.1038/mp.2015.53

43. Moncrieff J, Kirsch I. Empirically derived criteria cast doubt on the clinical significance of antidepressant-placebo differences. Contemp Clin Trials (2015) 43:60-2. doi:10.1016/j.cct.2015.05.005

44. Cuijpers P, Cristea IA. What if a placebo effect explained all the activity of depression treatments? World Psychiatry (2015) 14:310-1. doi:10.1002/wps. 20249

45. Ioannidis JP. Effectiveness of antidepressants: an evidence myth constructed from a thousand randomized trials? Philos Ethics Humanit Med (2008) 3:14. doi:10.1186/1747-5341-3-14 
46. Moncrieff J. Are antidepressants as effective as claimed? No, they are not effective at all. Can J Psychiatry (2007) 52:96-7; discussion 102. doi:10.1177/ 070674370705200204

47. Chen JA, Papakostas GI, Youn SJ, Baer L, Clain AJ, Fava M, et al. Association between patient beliefs regarding assigned treatment and clinical response: reanalysis of data from the Hypericum Depression Trial Study Group. J Clin Psychiatry (2011) 72:1669-76. doi:10.4088/JCP.10m06453

48. Hrobjartsson A, Thomsen AS, Emanuelsson F, Tendal B, Hilden J, Boutron I, et al. Observer bias in randomized clinical trials with measurement scale outcomes: a systematic review of trials with both blinded and nonblinded assessors. CMAJ (2013) 185:E201-11. doi:10.1503/cmaj.120744

49. Khan A, Faucett J, Lichtenberg P, Kirsch I, Brown WA. A systematic review of comparative efficacy of treatments and controls for depression. PLoS One (2012) 7:e41778. doi:10.1371/journal.pone.0041778

50. Gotzsche PC. Why I think antidepressants cause more harm than good. Lancet Psychiatry (2014) 1(2):104-6. doi:10.1016/S2215-0366(14)70280-9

51. Barbui C, Furukawa TA, Cipriani A. Effectiveness of paroxetine in the treatment of acute major depression in adults: a systematic re-examination of published and unpublished data from randomized trials. CMAJ (2008) 178:296-305. doi:10.1503/cmaj.070693

52. de Vries YA, Roest AM, Beijers L, Turner EH, de Jonge P. Bias in the reporting of harms in clinical trials of second-generation antidepressants for depression and anxiety: a meta-analysis. Eur Neuropsychopharmacol (2016) 26(11):1752-9. doi:10.1016/j.euroneuro.2016.09.370

53. Gartlehner G, Wagner G, Matyas N, Titscher V, Greimel J, Lux L, et al. Pharmacological and non-pharmacological treatments for major depressive disorder: review of systematic reviews. BMJ Open (2017) 7:e014912. doi:10.1136/bmjopen-2016-014912

54. Pigott HE, Leventhal AM, Alter GS, Boren JJ. Efficacy and effectiveness of antidepressants: current status of research. Psychother Psychosom (2010) 79:267-79. doi:10.1159/000318293

55. Deshauer D, Moher D, Fergusson D, Moher E, Sampson M, Grimshaw J. Selective serotonin reuptake inhibitors for unipolar depression: a systematic review of classic long-term randomized controlled trials. CMAJ (2008) 178:1293-301. doi:10.1503/cmaj.071068

56. Geddes JR, Carney SM, Davies C, Furukawa TA, Kupfer DJ, Frank E, et al. Relapse prevention with antidepressant drug treatment in depressive disorders: a systematic review. Lancet (2003) 361:653-61. doi:10.1016/S01406736(03)12599-8

57. Sim K, Lau WK, Sim J, Sum MY, Baldessarini RJ. Prevention of relapse and recurrence in adults with major depressive disorder: systematic review and meta-analyses of controlled trials. Int J Neuropsychopharmacol (2015) 19:1-13. doi:10.1093/ijnp/pyv076

58. El-Mallakh RS, Gao Y, Jeannie Roberts R. Tardive dysphoria: the role of long term antidepressant use in-inducing chronic depression. Med Hypotheses (2011) 76:769-73. doi:10.1016/j.mehy.2011.01.020

59. Fava GA. Can long-term treatment with antidepressant drugs worsen the course of depression? JClin Psychiatry (2003) 64:123-33. doi:10.4088/JCP. v64n0204

60. Healy D. Treatment-induced stress syndromes. Med Hypotheses (2010) 74:764-8. doi:10.1016/j.mehy.2010.01.038

61. Fava GA, Bernardi M, Tomba E, Rafanelli C. Effects of gradual discontinuation of selective serotonin reuptake inhibitors in panic disorder with agoraphobia. Int J Neuropsychopharmacol (2007) 10:835-8. doi:10.1017/ S1461145706007462

62. Rosenbaum JF, Fava M, Hoog SL, Ascroft RC, Krebs WB. Selective serotonin reuptake inhibitor discontinuation syndrome: a randomized clinical trial. Biol Psychiatry (1998) 44:77-87. doi:10.1016/S0006-3223(98)00126-7

63. Fava GA, Gatti A, Belaise C, Guidi J, Offidani E. Withdrawal symptoms after selective serotonin reuptake inhibitor discontinuation: a systematic review. Psychother Psychosom (2015) 84:72-81. doi:10.1159/000370338

64. Baldessarini RJ, Tondo L, Ghiani C, Lepri B. Illness risk following rapid versus gradual discontinuation of antidepressants. Am J Psychiatry (2010) 167:934-41. doi:10.1176/appi.ajp.2010.09060880

65. Baldessarini RJ. Risks in discontinuation trials with antidepressants. JClin Psychiatry (2014) 75:e1443. doi:10.4088/JCP.14lr09255

66. Reid S, Barbui C. Long term treatment of depression with selective serotonin reuptake inhibitors and newer antidepressants. BMJ (2010) 340:c1468. doi:10.1136/bmj.c1468
67. Biesheuvel-Leliefeld KE, Kok GD, Bockting CL, Cuijpers P, Hollon SD, van Marwijk HW, et al. Effectiveness of psychological interventions in preventing recurrence of depressive disorder: meta-analysis and meta-regression. J Affect Disord (2015) 174:400-10. doi:10.1016/j.jad.2014.12.016

68. De Maat S, Dekker J, Schoevers R, De Jonghe F. Relative efficacy of psychotherapy and pharmacotherapy in the treatment of depression: a meta-analysis. Psychother Res (2006) 16:566-78. doi:10.1080/10503300600756402

69. Hughes S, Cohen D. A systematic review of long-term studies of drug treated and non-drug treated depression. JAffect Disord (2009) 118:9-18. doi:10.1016/j.jad.2009.01.027

70. Bockting CLH, ten Doesschate MC, Spijker J, Spinhoven P, Koeter MWJ, Schene AH, et al. Continuation and maintenance use of antidepressants in recurrent depression. Psychother Psychosom (2008) 77:17-26. doi:10.1159/ 000110056

71. Goldberg D, Privett M, Ustun B, Simon G, Linden M. The effects of detection and treatment on the outcome of major depression in primary care: a naturalistic study in 15 cities. Br J Gen Pract (1998) 48:1840-4.

72. Ronalds C, Creed F, Stone K, Webb S, Tomenson B. Outcome of anxiety and depressive disorders in primary care. Br J Psychiatry (1997) 171:427-33. doi:10.1192/bjp.171.5.427

73. Gardarsdottir H, Egberts TC, Stolker JJ, Heerdink ER. Duration of antidepressant drug treatment and its influence on risk of relapse/recurrence: immortal and neglected time bias. Am JEpidemiol (2009) 170:280-5. doi:10.1093/ aje/kwp142

74. Hammad TA, Laughren T, Racoosin J. Suicidality in pediatric patients treated with antidepressant drugs. Arch Gen Psychiatry (2006) 63:332-9. doi:10.1001/ archpsyc.63.3.332

75. Sharma T, Guski LS, Freund N, Gotzsche PC. Suicidality and aggression during antidepressant treatment: systematic review and meta-analyses based on clinical study reports. BMJ (2016) 352:i65. doi:10.1136/bmj.i65

76. Stone M, Laughren T, Jones ML, Levenson M, Holland PC, Hughes A, et al. Risk of suicidality in clinical trials of antidepressants in adults: analysis of proprietary data submitted to US Food and Drug Administration. BMJ (2009) 339:b2880. doi:10.1136/bmj.b2880

77. Hetrick SE, McKenzie JE, Cox GR, Simmons MB, Merry SN. Newer generation antidepressants for depressive disorders in children and adolescents Cochrane Database Syst Rev (2012) 11:CD004851. doi:10.1002/14651858. CD004851.pub3

78. Aursnes I, Tvete IF, Gaasemyr J, Natvig B. Even more suicide attempts in clinical trials with paroxetine randomised against placebo. BMC Psychiatry (2006) 6:55. doi:10.1186/1471-244X-6-55

79. Baldessarini RJ, Lau WK, Sim J, Sum MY, Sim K. Suicidal risks in reports of long-term controlled trials of antidepressants for major depressive disorder II. Int J Neuropsychopharmacol (2017) 20:281-4. doi:10.1093/ijnp/pyw092

80. Fergusson D, Doucette S, Glass KC, Shapiro S, Healy D, Hebert P, et al. Association between suicide attempts and selective serotonin reuptake inhibitors: systematic review of randomised controlled trials. BMJ (2005) 330:396. doi:10.1136/bmj.330.7488.396

81. Gunnell D, Saperia J, Ashby D. Selective serotonin reuptake inhibitors (SSRIs) and suicide in adults: meta-analysis of drug company data from placebo controlled, randomised controlled trials submitted to the MHRA's safety review. BMJ (2005) 330:385. doi:10.1136/bmj.330.7488.385

82. Maund E, Tendal B, Hrobjartsson A, Jorgensen KJ, Lundh A, Schroll J, et al. Benefits and harms in clinical trials of duloxetine for treatment of major depressive disorder: comparison of clinical study reports, trial registries, and publications. BMJ (2014) 348:g3510. doi:10.1136/bmj.g3510

83. Coupland C, Hill T, Morriss R, Arthur A, Moore M, Hippisley-Cox J. Antidepressant use and risk of suicide and attempted suicide or self harm in people aged 20 to 64: cohort study using a primary care database. BMJ (2015) 350:h517. doi:10.1136/bmj.h517

84. Bjorkenstam C, Moller J, Ringback G, Salmi P, Hallqvist J, Ljung R. An association between initiation of selective serotonin reuptake inhibitors and suicide - a nationwide register-based case-crossover study. PLoS One (2013) 8:e73973. doi:10.1371/journal.pone.0073973

85. Stone MB. The FDA warning on antidepressants and suicidality - why the controversy? N Engl J Med (2014) 371:1668-71. doi:10.1056/NEJMp1411138

86. Coupland C, Dhiman P, Morriss R, Arthur A, Barton G, Hippisley-Cox J. Antidepressant use and risk of adverse outcomes in older people: population based cohort study. BMJ (2011) 343:d4551. doi:10.1136/bmj.d4551 
87. Smoller JW, Allison M, Cochrane BB, Curb JD, Perlis RH, Robinson JG, et al. Antidepressant use and risk of incident cardiovascular morbidity and mortality among postmenopausal women in the Women's Health Initiative study. Arch Intern Med (2009) 169:2128-39. doi:10.1001/archinternmed.2009.436

88. Maslej MM, Bolker BM, Russell MJ, Eaton K, Durisko Z, Hollon SD, et al. The mortality and myocardial effects of antidepressants are moderated by preexisting cardiovascular disease: a meta-analysis. Psychother Psychosom (2017) 86:268-82. doi:10.1159/000477940

89. Olfson M, Blanco C, Marcus SC. Treatment of adult depression in the United States. JAMA Intern Med (2016) 176:1482-91. doi:10.1001/ jamainternmed.2016.5057

90. Mojtabai R, Olfson M. Proportion of antidepressants prescribed without a psychiatric diagnosis is growing. Health Aff (2011) 30:1434-42. doi:10.1377/ hlthaff.2010.1024

91. Andrews PW, Thomson JA Jr, Amstadter A, Neale MC. Primum non nocere: an evolutionary analysis of whether antidepressants do more harm than good. Front Psychol (2012) 3:117. doi:10.3389/fpsyg.2012.00117

92. Carvalho AF, Sharma MS, Brunoni AR, Vieta E, Fava GA. The safety, tolerability and risks associated with the use of newer generation antidepressant drugs: a critical review of the literature. Psychother Psychosom (2016) 85:270-88. doi:10.1159/000447034

93. Fournier JC, DeRubeis RJ, Hollon SD, Dimidjian S, Amsterdam JD, Shelton RC, et al. Antidepressant drug effects and depression severity: a patient-level meta-analysis. JAMA (2010) 303:47-53. doi:10.1001/jama.2009.1943

94. Kaptchuk TJ. The double-blind, randomized, placebo-controlled trial: gold standard or golden calf? J Clin Epidemiol (2001) 54:541-9. doi:10.1016/ S0895-4356(00)00347-4
95. Furukawa TA, Cipriani A, Atkinson LZ, Leucht S, Ogawa Y, Takeshima $\mathrm{N}$, et al. Placebo response rates in antidepressant trials: a systematic review of published and unpublished double-blind randomised controlled studies. Lancet Psychiatry (2016) 3:1059-66. doi:10.1016/S2215-0366(16) 30307-8

96. Rush AJ, Trivedi M, Carmody TJ, Biggs MM, Shores-Wilson K, Ibrahim H, et al. One-year clinical outcomes of depressed public sector outpatients: a benchmark for subsequent studies. Biol Psychiatry (2004) 56:46-53. doi:10.1016/j.biopsych.2004.04.005

97. Fava GA. Rational use of antidepressant drugs. Psychother Psychosom (2014) 83:197-204. doi:10.1159/000362803

98. Johnell K, Jonasdottir Bergman G, Fastbom J, Danielsson B, Borg N, Salmi P. Psychotropic drugs and the risk of fall injuries, hospitalisations and mortality among older adults. Int J Geriatr Psychiatry (2017) 32:414-20. doi:10.1002/ gps. 4483

Conflict of Interest Statement: The author declares that the research was conducted in the absence of any commercial or financial relationships that could be construed as a potential conflict of interest.

Copyright (c) 2017 Hengartner. This is an open-access article distributed under the terms of the Creative Commons Attribution License (CC BY). The use, distribution or reproduction in other forums is permitted, provided the original author(s) or licensor are credited and that the original publication in this journal is cited, in accordance with accepted academic practice. No use, distribution or reproduction is permitted which does not comply with these terms. 